\title{
Hybrid electric vehicle drives fitted with combustion engines
}

Two generic types of hybrid drive fitted with Internal Combustion Engines (ICE) have been considered. The first type is a serial one. The second type is a parallel drive system represented by two subtypes: a compact hybrid drive with two degrees of freedom planetary transmission and a split-sectional drive.

Based on example hybrid drives for city buses, a computer simulation is an appropriate method as a design tool. Special stress has been put on the compact hybrid drive with a planetary transmission, which seems to be the most advantageous. A serial hybrid drive has also been discussed in detail because currently this solution is the most common one applied in contemporary hybrid buses.

Key words: hybrid electric vehicle, combustion engines, computer simulation

\section{Projektowanie napędów hybrydowych pojazdów z silnikiem spalinowym}

W artykule zanalizowano podstawowe typy napędów hybrydowych z silnikami spalinowymi: szeregowy oraz równoległy, reprezentowany przez uktad z przektadnia planetarna o dwóch stopniach swobody.

Analize przeprowadzono na przyktadzie napędu autobusu miejskiego. Symulację komputerowa wybrano jako najlepsza. metodę projektowania. Szczególnq uwagę zwrócono na napęd z przektadnia planetarna, ponieważ takie rozwiąanie wydaje się najbardziej efektywne energetycznie. Omówiono również napęd szeregowy, gdyż jest on stosowany w istniejacych autobusach miejskich.

Słowa kluczowe: napęd hybrydowy, silnik spalinowy, symulacja komputerowa

\section{Method and objectives}

The block diagram of the schematics of computer analysis - simulation test is shown in Fig. 1.

Power $\mathrm{N}(\mathrm{t})$ and velocity $\mathrm{V}(\mathrm{t})$ taken from a driving cycle on the vehicle wheel are the input vector $\mathbf{u}(\mathrm{t})$

$$
\mathbf{u}(\mathbf{t})=\left[\begin{array}{l}
N(t) \\
V(t)
\end{array}\right]
$$

Model equations depicting drive components determine the output vector $\mathbf{x}(\mathrm{t})$

\section{Metoda i cele}

Rysunek 1 przedstawia schemat stanowiący podstawę symulacji - analizy komputerowej.

Wektorem wejściowym u(t) są zależności opisujące moc $\mathrm{N}(\mathrm{t})$ oraz prędkości $\mathrm{V}(\mathrm{t})$ na kole pojazdu, odpowiednio do realizowanego cyklu jazdy. Jako wektor wyjściowy $\mathbf{x}(\mathrm{t})$ stanowią zależności opisujące modele matematyczne komponentów napędu hybrydowego z uwzględnieniem ich funkcji sterowania odpowiednio do realizowanego cyklu jazdy $(1,2)$.

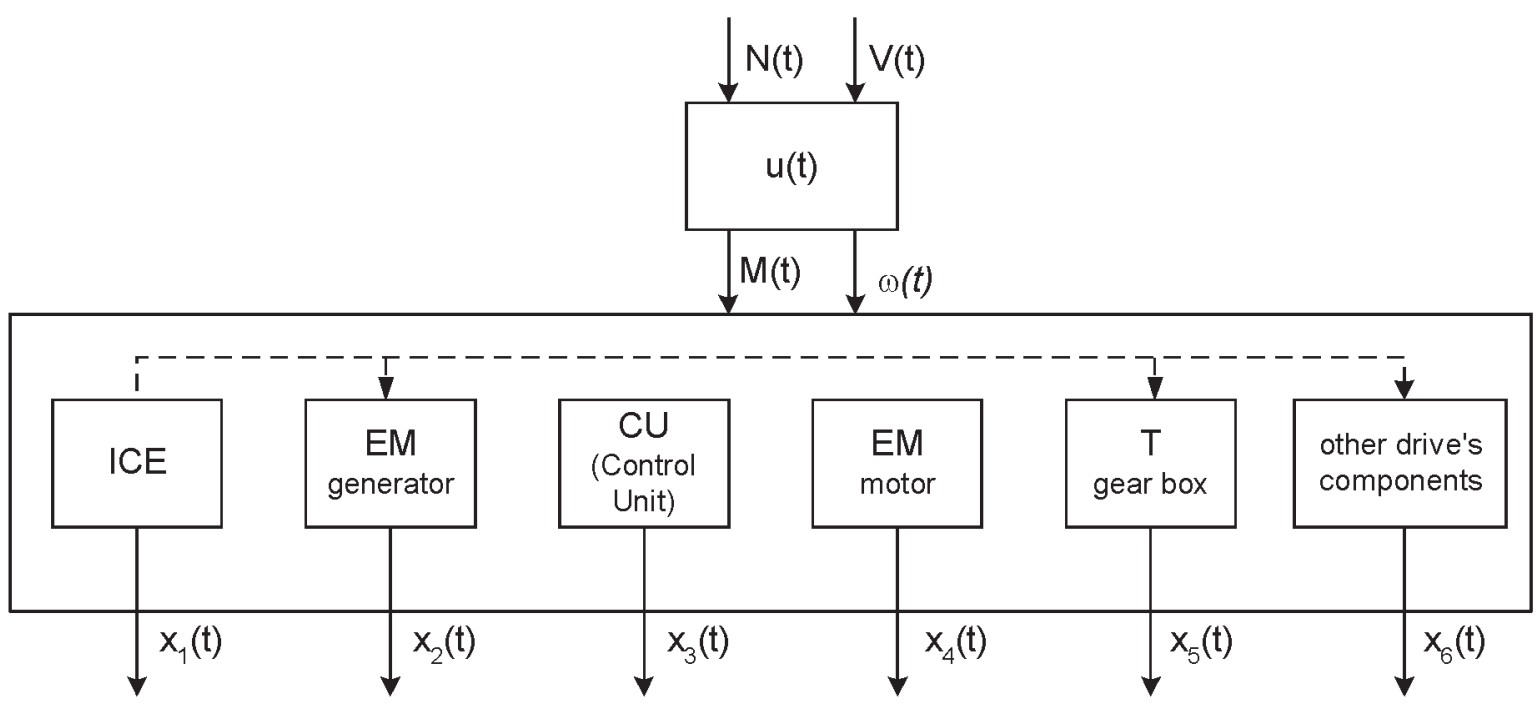

Fig. 1. The sketch of schematics of a hybrid drive used for a computer simulation (dashed lines show the possibility of different combination of drive configuration including serial and parallel)

Rys. 1. Schemat blokowy napędu hybrydowego wykorzystany do badań symulacyjnych (linie przerywane prezentują możliwość uzyskania różnych struktur hybrydowych tacznie z szeregową i równoległa) 


$$
\mathbf{x}(t)=\left[\begin{array}{l}
\mathrm{x}_{1}(\mathrm{t}) \\
\mathrm{x}_{2}(\mathrm{t}) \\
\vdots \\
\mathrm{x}_{\mathrm{n}}(\mathrm{t})
\end{array}\right]
$$

where $\mathrm{x}_{1}, \mathrm{x}_{2} \ldots \mathrm{x}_{\mathrm{n}}$ are functions of time, such as flux, current, torque, angular velocity and other variables occurring in individual models.

What is described above requires a numerical solution. Gear's method has been used to solve different and nonlinear algebraic differential equations (see [3, 4]). In order to use the discrete variable method, it's necessary to integrate a group of equations described by a mixture of ordinary differential equations, nonlinear equations and linear equations.

Input data (input vector) are generated from a Warsaw Driving Cycle.

The map of selected diesel engines, electric machine models of AC induction and PM, Vector Field Oriented method for control of the motors, battery models for lead-acid, NiMH and Li-ion, models of planetary gear, a differential gear, and other reducers have been used in the simulation study.

The main objective of the simulation study is to compare performances of selected hybrid drive architectures. Dynamic modelling and simulation are very effective tools for designing hybrid drives.

The design process of a hybrid drive focuses on the following steps:

1. Selecting and adjusting the best drive architecture considering the following terms: minimum number of components, maximum efficiency, minimum fuel and electricity consumption connected with emission.

2. Working out the control strategy adjusted to the considered drive architecture.

3. Determining the parameters of a hybrid drive as follows:

- fuel consumption $\left(\mathrm{dm}^{3} / 100 \mathrm{~km}\right)$

- ICE operating points located in its map regarding the analyzed driving cycle

- battery BCL operating range according to a computed EMF and internal resistance

- modifications of ICE torque, angular velocity and power

- modifications of motor component's $u_{q}, u_{d}$ and $i_{q}, i_{d}$

- modifications of battery current, voltage, power and BCL

- calculation of the maximum boundary value of the battery, Coulomb capacity $(\mathrm{A} \cdot \mathrm{h})$ exchange regarding the analyzed driving cycle

- final assumption of the battery capacity and the nominal voltage of the battery pack

- final adjustment of the mechanical transmission ratio.

The optimal adjustment of a hybrid electric drive fitted with an ICE is possible only by a computer simulation method. The target function is to minimize the powertrain internal losses. The quality factors are fuel consumption by ICE and final electricity consumption through battery charg- gdzie $x_{1}, x_{2} \ldots x_{n}$ są to funkcje czasu, takie jak strumień magnetyczny, prąd, moment obrotowy, prędkość kątowa i inne zmienne, zależnie od modeli matematycznych poszczególnych komponentów napędu.

Do obliczeń numerycznych zastosowano metodę Geara, w celu rozwiązania układów nieliniowych równań różniczkowych i algebraicznych.

Wektor wejściowy - dane wejściowe są generowane z przykładowego cyklu jazdy autobusu miejskiego - opracowanego Cyklu Warszawskiego.

Mapy i modele wybranych silników wysokoprężnych, elektrycznych, akumulatorów niklowo-wodorkowych, litowo-jonowych, przekładni planetarnej i innych zostały wykorzystane do badań symulacyjnych.

Głównym celem badań symulacyjnych jest porównanie osiągów (zużycia energii) zaprojektowanych metodą rozważanych napędów hybrydowych. Modelowanie dynamiczne i badania symulacyjne okazały się bardzo dobrym narzędziem projektowania struktur napędów hybrydowych.

Przyjęto następującą procedurę $\mathrm{w}$ procesie projektowania napędu hybrydowego:

1) wybór i właściwy dobór najlepszej struktury napędu przy uwzględnieniu warunków: minimalizacja liczby komponentów, maksymalizacja sprawności, minimalizacja zużycia paliwa i elektryczności, co związane jest ze zmniejszeniem emisji,

2) opracowanie odpowiedniej strategii sterowania dobranej do struktury napędu,

3) ustalenie następujących parametrów napędu hybrydowego:

- zużycie paliwa na $100 \mathrm{~km}$

- wyznaczenie punktów pracy silnika odpowiednio do analizowanego cyklu jazdy

- określenie zakresu zmian naładowania akumulatora SOC odpowiednio do wyznaczonej siły elektromotorycznej i rezystancji wewnętrznej

- określenie zmian wartości momentu, prędkości kątowej i mocy silnika spalinowego

- określenie zmian wartości składowych napięcia $\mathrm{u}_{\mathrm{q}} \mathrm{i} \mathrm{u}_{\mathrm{d}}$ prądu $i_{q}, i_{d}$ silnika elektrycznego

- określenie zmian wartości prądu napięcia, mocy i SOC akumulatorów

- obliczenie ograniczeń dla akumulatorów odniesionych do ich pojemności kulombowskiej $(\mathrm{A} \cdot \mathrm{h})$ podczas realizowanego cyklu jazdy

- wyznaczenie końcowe właściwej pojemności i nominalnego napięcia baterii akumulatorów

- dobór końcowy przełożeń mechanicznych.

Wyznaczenie optymalnych wartości parametrów wymienionych wyżej w napędzie hybrydowym z silnikiem spalinowym jest możliwe tylko dzięki zastosowaniu metody komputerowej symulacji. Funkcją celu jest minimalizacja strat wewnętrznych napędu, zaś wskaźnikami jakości są zużycie paliwa przez silnik spalinowy i końcowe zużycie energii elektrycznej przy doładowywaniu baterii. Szczegółowe ograniczenia muszą być opisane. W artykule główny nacisk położono na modelowanie silnika spalinowego 
ing. Detailed limitations have to be described. This paper is focused on ICE modelling respective to hybrid drive simulation requirements. Obviously, other component models of the powertrain are used, but not explained $[1,2]$. The paper includes simulation tests for two most common hybrid drive systems. The results of those simulations are limited only to ICE fuel consumption and electricity consumption. In the last case the Battery Charge Level (BCL) has to obtain the same value in the beginning and at the end of the driving cycle. Simulated hybrid drives were properly adjusted to optimize its component parameters, which caused a minimum ICE fuel consumption and a battery charge balance during the assumed driving cycle.

\section{Internal combustion engine modeling}

The real modelling of ICE is very complex because the object is strongly nonlinear. For this reason, the approximation functions depicted by high stage of multinomial or by set of "spline" functions are practically useless for simulating the drive system consisting of few mechanical-electrical components. An original method (Hajduga, Szumanowski) of dynamic modelling of ICE has been proposed.

The background of ICE modelling is the experimental data as static engine torque characteristics shown in Fig. 2.

As is shown, every angle torque curve local maximum is replaced in the direction of higher angular velocity value. This makes these curves asymmetric. The best way is to approximate a torque characteristics by a square power multinomial. This is possible if special transformation function is used [2].

The angle $\phi_{\text {te }}$ is described as a function of local maximum torque value for a certain fixed constant $\alpha_{\text {te }}$ position, related to a maximum-maximorum torque value.

The approximation of the transformed engine torque by a square power multinomial is possible if the basic set of equations is used.

$$
\varphi_{\mathrm{te}}\left(\alpha_{\mathrm{te}}\right)=\mathbf{f}\left(\frac{\mathrm{M}_{\text {max }}\left(\alpha_{\mathrm{te}}\right)}{\mathrm{M}_{\text {max }}\left(\alpha_{\mathrm{temax}}\right)}\right), \quad \alpha_{\text {temax }}=90^{\circ}
$$

The transformed torque of the engine is:

$$
\mathrm{M}_{\mathrm{te}}{ }^{\prime}\left(\omega_{\mathrm{te}}{ }^{\prime}\right)=\mathrm{a}\left(\alpha_{\mathrm{te}}\right) \omega_{\mathrm{te}}{ }^{\prime 2}+\mathrm{b}\left(\alpha_{\mathrm{te}}\right) \omega_{\mathrm{te}}{ }^{\prime}+\mathrm{c}\left(\alpha_{\mathrm{te}}\right)
$$

where: $\mathrm{a}\left(\alpha_{\mathrm{te}}\right), \mathrm{b}\left(\alpha_{\mathrm{te}}\right), \mathrm{c}\left(\alpha_{\mathrm{te}}\right)$ are coefficients of equation obtained by the approximation method, $\omega_{\mathrm{te}}$ ' is the transformed angular velocity of engine crankshaft.

$$
\begin{aligned}
& \mathrm{a}\left(\alpha_{\mathrm{te}}\right)=\mathrm{a}_{\mathrm{m}} \alpha_{\mathrm{te}}{ }^{\mathrm{m}}+\mathrm{a}_{\mathrm{m}-1} \alpha_{\mathrm{te}}{ }^{\mathrm{m}-1}+\ldots+\mathrm{a}_{1} \alpha_{\mathrm{te}}+\mathrm{a}_{0} \\
& \mathrm{~b}\left(\alpha_{\mathrm{te}}\right)=\mathrm{b}_{\mathrm{n}} \alpha_{\mathrm{te}}{ }^{\mathrm{n}}+\mathrm{b}_{\mathrm{n}-1} \alpha_{\mathrm{te}}{ }^{\mathrm{n}-1}+\ldots+\mathrm{b}_{1} \alpha_{\mathrm{te}}+\mathrm{b}_{0} \\
& \mathrm{c}\left(\alpha_{\mathrm{te}}\right)=\mathrm{c}_{\mathrm{k}} \alpha_{\mathrm{te}}{ }^{\mathrm{k}}+\mathrm{c}_{\mathrm{k}-1} \alpha_{\mathrm{te}}{ }^{\mathrm{k}-1}+\ldots+\mathrm{c}_{1} \alpha_{\mathrm{te}}+\mathrm{c}_{0}
\end{aligned}
$$

The transformed equations after basic coordinates rotated into $\varphi_{\text {te }}$ angle are as follows:

$$
\begin{aligned}
& \omega_{\mathrm{te}}{ }^{\prime}\left(\varphi_{\mathrm{te}}\right)=\omega_{\mathrm{te}} \cos \varphi_{\mathrm{te}}-\mathrm{M}_{\mathrm{te}} \sin \varphi_{\mathrm{te}} \\
& \varphi\left(\alpha_{\mathrm{te}}\right)=\mathrm{a}_{\alpha} \alpha_{\mathrm{te}}{ }^{\mathrm{m}}+\mathrm{b}_{\alpha} \alpha_{\mathrm{te}}{ }^{\mathrm{m}-1}+\mathrm{c}_{\alpha} \alpha_{\mathrm{te}}{ }^{\mathrm{m}-2}+\ldots+\mathrm{d}_{\alpha} \alpha_{\mathrm{te}}+\mathrm{e}_{\alpha}
\end{aligned}
$$

odpowiednio do wymagań stawianych przez badania symulacyjne i napęd hybrydowy. Oczywiście modelowanie innych komponentów napędu nie zostało wyjaśnione w tym artykule (patrz [1, 2]).

Artykuł przedstawia badania symulacyjne dla dwóch najbardziej popularnych rodzajów napędu hybrydowego. Prezentacja wyników tych badań została, z konieczności, ograniczona tylko do zużycia paliwa przez silnik spalinowy i elektryczności przez baterię. W tym ostatnim przypadku stopień naładowania baterii musi być utrzymany na końcu cyklu jazdy o takiej samej wartości jak na początku. Poddane badaniom symulacyjnym napędy hybrydowe były odpowiednio dobrane, a ich optymalne komponenty odpowiednio wyznaczone, aby otrzymać minimalne zużycie paliwa i równowagę naładowania baterii.

\section{Modelowanie silnika spalinowego}

Modelowanie silnika spalinowego jest bardzo skomplikowane ze względu na bardzo dużą nieliniowość obiektu. $\mathrm{Z}$ tego powodu aproksymacje wielomianami wyższych stopni lub zestawami funkcji ,spline” są nieużyteczne w sytuacji wykonywania badań symulacyjnych układów zawierających wiele komponentów mechanicznych i elektrycznych. W zamian zastosowano oryginalną metodę (Hajduga, Szumanowskiego) dynamicznego modelowania silnika. Podstawą modelowania są wyniki badań eksperymentalnych i statyczna charakterystyka momentu (rys. 2).

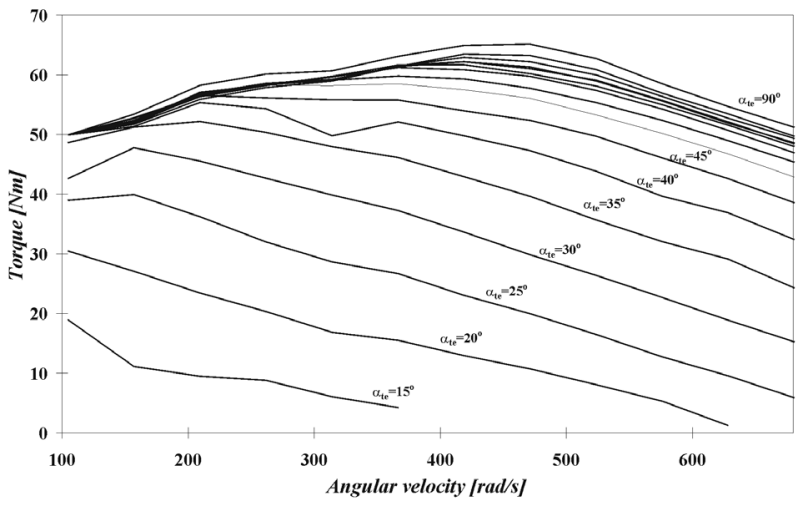

Fig. 2. The engine experimental torque characteristic $\left(\alpha_{t e}\right.$ is the "virtual throttle valve" position corresponding to injected volume of fuel)

Rys. 2. Eksperymentalna charakterystyka momentu silnika spalinowego ( $a_{\text {te }}$ jest , wirtualnym katem otwarcia przepustnicy” odpowiadajacym dawce dostarczanego paliwa)

Na rysunku 2 widać, że lokalne maksima krzywej momentu przesuwają się w kierunku większej prędkości obrotowej. Krzywe te są więc asymetryczne. Najlepszą metodą jest aproksymowanie charakterystyk momentu wielomianem kwadratowym. Jest to możliwe wtedy, gdy użyta jest specjalna funkcja transformująca [2].

Kąt $\phi_{\text {te }}$ jest opisany jako funkcja lokalnego maksimum momentu dla ustalonej wartości $\alpha_{\text {te }}$, odniesionej do wartości maximum-maximorum momentu.

Metoda aproksymacji transformowanego momentu silnika przez wielomian kwadratowy jest możliwa wtedy, gdy użyty jest układ równań (3). 
where: $\mathrm{a}_{\alpha}, \mathrm{b}_{\alpha}, \mathrm{c}_{\alpha}, \mathrm{d}_{\alpha}, \mathrm{e}_{\alpha}-$ coefficients necessary for determining $\mathrm{M}_{\text {te } \max }\left(\alpha_{\text {te }}\right)$ according to equation (3).

All coefficients of equations (5), (6) should be determined individually for individual type of engine.

After transformation from $\omega_{\mathrm{te}}-\mathrm{M}_{\mathrm{te}}$ to $\omega_{\mathrm{te}}{ }^{\prime}-\mathrm{M}_{\mathrm{te}}{ }^{\prime}$, it is necessary to turn back to real approximated torque curves in the following way:

the basic torque in an algebraic form is:

$$
M_{\mathrm{te}}=-\omega_{\mathrm{te}}{ }^{\prime} \sin \varphi_{\mathrm{te}}+\mathrm{M}_{\mathrm{te}}{ }^{\prime} \cos \varphi_{\mathrm{te}}
$$

where: $\omega_{\text {te }}$ ' - the transformed value of angular velocity of engine shaft; $\mathrm{M}_{\mathrm{te}}$ ' - the transformed value of engine torque; $\varphi_{\text {te }}$ - conversion angle determined by the real curve connecting the points of maximum real engine torque $M_{\text {te } \max }$ as the function of engine fuel valve open angle $\alpha_{\text {te }}$.

The mathematical model of ICE can be described by the following set of equations:

$$
\left\{\begin{array}{l}
\mathrm{M}_{\mathrm{te}}=-\mathrm{c}_{\omega} \omega_{\mathrm{te}}^{\prime} \sin \varphi_{\mathrm{te}}+\mathrm{M}_{\mathrm{te}}^{\prime} \cos \varphi_{\mathrm{te}} \\
\mathrm{J} \frac{\mathrm{d} \omega_{\mathrm{te}}}{\mathrm{dt}}=\mathrm{M}_{\mathrm{te}}-\mathrm{M}(\mathrm{t})
\end{array}\right.
$$

where: $M(t)$ - external load torque reduced to the engine shaft, $\mathrm{c}_{\omega}=1 \mathrm{~N} \cdot \mathrm{m} \cdot \mathrm{s}-$ calculated proportionality constant.

The approximated torque characteristics are shown in Fig. 2, and the mathematical model of engine using the presented method is shown in Fig. 3.

The maximum error of the mathematical model compared with the experimental data is less than $15 \%$ for all family of curves.

The presented methodology is very useful for complex drive powertrain and it can be preferred for hybrid drive modeling in the case of a simplified computer calculation. After modeling, it is possible to obtain a "map" of real ICE by simulation and lab bench-tests. The "map" can also be used for a simulation study of a hybrid drive. A diesel engine model is included because of its original approach based on the experimental data (Fig. 4).

The block named ENGINE MAP consists of the approximation module of the engine performance and generates the following set of equations:

$$
\left.\begin{array}{l}
M_{\text {te }}=f\left(G_{e}, n\right) \\
M_{t e}=p_{e} V_{e} / 4 \pi \\
p_{e t}=f\left(G_{e}\right)
\end{array}\right\}
$$

The torque balance equation has the form:

$$
J_{\mathrm{e}} \frac{\mathrm{d} \omega}{\mathrm{dt}}=\mathrm{M}_{\mathrm{te}}(\mathrm{q}, \omega)-\mathrm{M}_{1}(\mathrm{t})
$$

The block PUMP MAP approximates the fuel injection characteristic according to:

$$
\mathrm{G}_{\mathrm{te}}=\mathrm{f}\left(\mathrm{x}_{\mathrm{p}}, \mathrm{n}\right)
$$

where: $\mathrm{n}$ - engine speed [rpm], $\omega$ - engine angular velocity $[\mathrm{rad} / \mathrm{s}], \mathrm{M}_{\mathrm{te}}-$ effective driving torque $[\mathrm{N} \cdot \mathrm{m}], \mathrm{J}_{\mathrm{te}}-$ reduced
Transformowany moment silnika opisany jest jako (4), gdzie: $\mathrm{a}\left(\alpha_{\mathrm{te}}\right), \mathrm{b}\left(\alpha_{\mathrm{te}}\right), \mathrm{c}\left(\alpha_{\mathrm{te}}\right)$ - równanie (5) - są współczynnikami równania uzyskanego metodą aproksymacji, $\omega_{\text {te }}$ ' jest transformowaną prędkością obrotową wału silnika.

Transformowane równania po obrocie układu współrzędnych o kąt $\varphi_{\text {te }}$ mają postać równań (6),

gdzie: $\mathrm{a}_{\alpha}, \mathrm{b}_{\alpha}, \mathrm{c}_{\alpha}, \mathrm{d}_{\alpha}, \mathrm{e}_{\alpha}$ - współczynniki niezbędne do wyznaczenia $\mathrm{M}_{\text {te } \max }\left(\alpha_{\mathrm{te}}\right)$ według równania (3).

Wszystkie współczynniki równań (5), (6) powinny być wyznaczone osobno dla konkretnego typu silnika.

Po wykonaniu transformacji $\mathrm{z} \omega_{\mathrm{te}}-\mathrm{M}_{\mathrm{te}}$ do $\omega_{\mathrm{te}}{ }^{\text {' }}-\mathrm{M}_{\mathrm{te}}$,' konieczny jest powrót do rzeczywistego momentu aproksymowanego w następujący sposób:

Moment wyrażony w formie algebraicznej określony jest jako (7),

gdzie: $\omega_{\text {te }}{ }^{\prime}-$ transformowana wartość prędkości obrotowej wału silnika, $\mathrm{M}_{\mathrm{te}}{ }^{\prime}$ - transformowana wartość momentu silni$\mathrm{ka}, \varphi_{\text {te }}$ - kąt konwersji wyznaczony przez rzeczywistą krzywą łączącą poszczególne punkty maksimum momentu silnika $\mathrm{M}_{\text {te } \max }$ jako funkcji kąta otwarcia przepustnicy $\alpha_{\text {te }}$.

Model matematyczny silnika spalinowego może być opisany równaniami (8),

gdzie: $M(t)$ - moment zewnętrzny zredukowany do wału silnika, $\mathrm{c}_{\omega}=1 \mathrm{~N} \cdot \mathrm{m} \cdot \mathrm{s}-$ współczynnik proporcjonalności.

Aproksymowane charakterystyki momentu pokazano na rys. 2, a model silnika wykorzystujący zaprezentowaną metodę na rys. 3 .

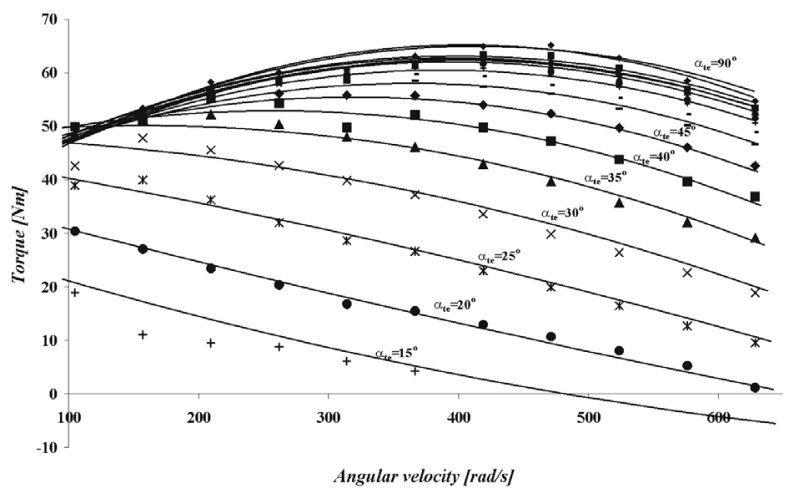

Fig. 3. The approximated engine torque characteristics Rys. 3. Aproksymowane charakterystyki momentu silnika

Maksymalny błąd modelu w porównaniu do danych eksperymentalnych wynosi poniżej 15\% dla wszystkich analizowanych krzywych. Zaprezentowana metoda może być wykorzystywana w modelowaniu skomplikowanych układów napędowych, szczególnie hybrydowych. W wyniku modelowania można uzyskać „,mapy” rzeczywistego silnika, które mogą być używane w badaniach symulacyjnych napędów hybrydowych. Poniżej przedstawiono przykład modelowania silnika o ZS na podstawie danych eksperymentalnych (rys. 4). 
moment of inertia of engine-generator set $\left[\mathrm{kg} \cdot \mathrm{m}^{2}\right], \mathrm{G}_{\mathrm{te}}-$ delivery of fuel pump (fuel consumption per hour) $[\mathrm{kg} / \mathrm{h}]$, $\mathrm{x}_{\mathrm{p}}$ - fuel pump rack position, $\mathrm{u}-$ governor control lever position (acceleration \& deceleration), $\mathrm{q}$ - portion of fuel $\left[\mathrm{m}^{3} /\right.$ injetion], $\mathrm{M}_{1}-$ external load torque $[\mathrm{N} \cdot \mathrm{m}], \mathrm{P}_{\mathrm{te}}-$ effective pressure $[\mathrm{MPa}], \mathrm{V}_{\text {te }}-$ volumetric engine factor $\left[\mathrm{m}^{3}\right]$.

\section{Serial hybrid drive}

Figure 5 shows the momentary power flow in a point electrically connecting ICE-Generator unit with the battery. The Control of the serial hybrid drive is focused on a proper ICE-Generator momentary voltage generation, whose voltage should be equal to the battery voltage at all times.

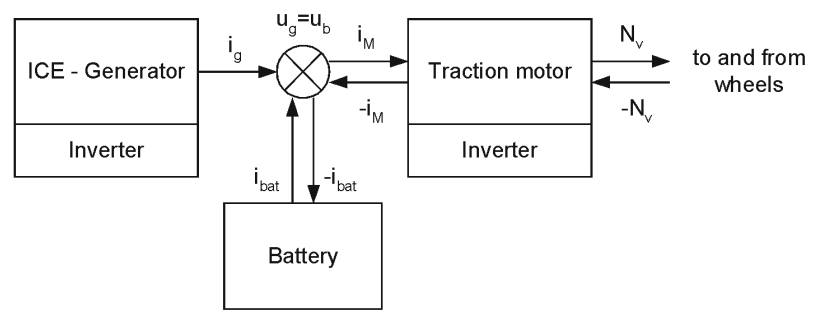

Fig. 5. Momentary power flowing through junction

Rys. 5. Chwilowy przeplyw mocy w punkcie połaczenia

where: $\mathrm{i}_{\mathrm{g}}, \mathrm{u}_{\mathrm{g}}-$ current and voltage of the generator, $\mathrm{i}_{\mathrm{b}}, \mathrm{u}_{\mathrm{b}}-$ current and voltage of the battery, $\mathrm{i}_{\mathrm{M}}, \mathrm{u}_{\mathrm{M}}$ - input current and voltage of the motor, $\mathrm{N}_{\mathrm{v}}$ - power proportional to the traction wheels power.

At any moment the power balance at the junction is described as follows:

\begin{tabular}{|l|l|}
\hline $\left.\begin{array}{l}i_{g}-i_{b}=i_{M} \rightarrow \text { when } n_{g}>n_{V} \\
i_{g}+i_{b}=i_{M} \rightarrow \text { when } n_{g}<n_{V}\end{array}\right\}$ & $\begin{array}{l}\text { vehicle acceleration, } n_{v}, n_{g}: \\
\text { momentary power of vehicle } \\
\text { and generator }\end{array}$ \\
\hline$i_{g}-i_{b}=-i_{M} \rightarrow$ for $-n_{V}$ & vehicle regenerative brake \\
\hline$i_{g}-i_{b}=0$ if $i_{M}=0 \rightarrow$ for $n_{V}=0$ & active vehicle stop \\
\hline$n_{g}=i_{g} u_{g}$ & momentary generator power \\
\hline
\end{tabular}
lows:

The power of the generator can be expressed as fol-

$$
\begin{aligned}
& \mathrm{n}_{\mathrm{g}}=\mathrm{i}_{\mathrm{g}} \mathrm{u}_{\mathrm{g}}=\left(\mathrm{e}_{\mathrm{g}}-\mathrm{i}_{\mathrm{g}} \mathrm{R}_{\mathrm{g}}\right) \mathrm{i}_{\mathrm{g}} \\
& \mathrm{e}_{\mathrm{g}}=\mathrm{f}\left(\psi, \omega_{\mathrm{g}}\right) \cong \mathrm{c} \psi(\omega)
\end{aligned}
$$

Finally, $n_{g}=c \psi\left(\omega_{g} i_{g}-i_{g}^{2} R_{g} \rightarrow \omega_{g}=\frac{n_{g}+i_{g}^{2} R_{g}}{c i_{g} \psi}\right.$

where: $\mathrm{e}_{\mathrm{g}}$ - momentary EMF value of the generator, $\mathrm{c}-$ proportionality factor, $\psi$ - magnetic flux, $\omega_{\mathrm{g}}$ - angular velocity of the generator, $\mathrm{R}_{\mathrm{g}}$ - internal resistance of the generator.

The angular velocity $\omega_{\mathrm{g}}$ of the generator is equal to that of ICE (directly connected by the shafts). The momentary electromagnetic torque of the generator $\left(\mathrm{m}_{\mathrm{g}}=\mathrm{c}_{1} \mathrm{i}_{\mathrm{g}} \psi\right)$ is proportional to the torque of $\operatorname{ICE}\left(\mathrm{m}_{\mathrm{ICE}}\right)$ and $\mathrm{m}_{\mathrm{g}}=\mathrm{m}_{\mathrm{ICE}} \cdot \eta(\eta<1$

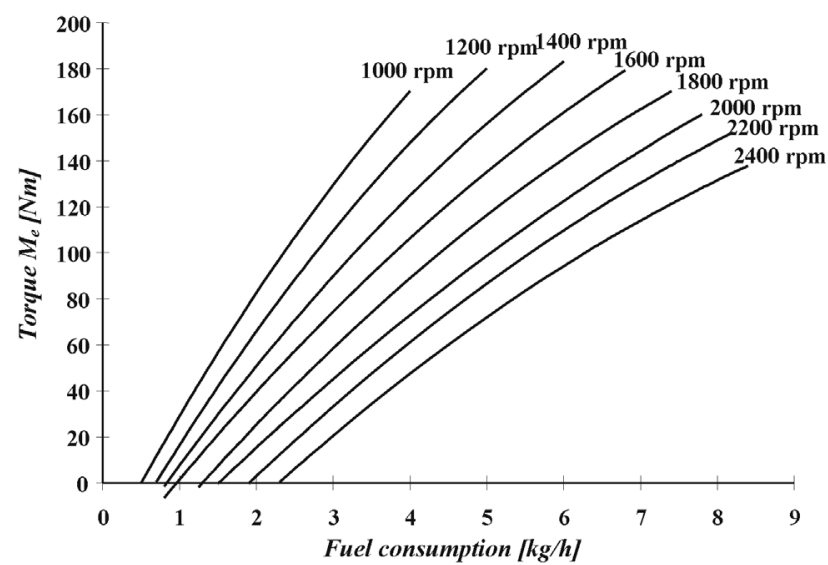

Fig. 4. The load function for the analyzed diesel engine Rys. 4. Funkcje obciążenia dla prezentowanego silnika ZS

Blok nazwany ENGINE MAP zawiera moduł aproksymujący warunki pracy silnika według równań (9).

Równowaga dynamiczna momentów opisana jest zależnością (10).

Blok PUMP MAP aproksymuje charakterystykę wtrysku paliwa według (11),

gdzie: $\mathrm{n}$ - prędkość wału silnika [obr/min], $\omega$ - prędkość wału silnika $[\mathrm{rad} / \mathrm{s}], \mathrm{M}_{\mathrm{te}}-$ moment efektywny $[\mathrm{N} \cdot \mathrm{m}], \mathrm{J}_{\mathrm{te}}$ - zredukowany moment bezwładności układu silnik-generator $\left[\mathrm{kg} \cdot \mathrm{m}^{2}\right], \mathrm{G}_{\mathrm{te}}-$ zużycie paliwa na godz. $[\mathrm{kg} / \mathrm{h}], \mathrm{x}_{\mathrm{p}}$ - pozycja pompy paliwa, q - dawka paliwa $\left[\mathrm{m}^{3} /\right.$ wtrysk], $\mathrm{M}_{1}$ - zewnętrzny moment obciążenia $[\mathrm{N} \cdot \mathrm{m}], \mathrm{P}_{\text {te }}$ - ciśnienie efektywne $[\mathrm{MPa}], \mathrm{V}_{\mathrm{te}}-$ pojemność silnika $\left[\mathrm{m}^{3}\right]$.

\section{Szeregowy napęd hybrydowy}

Rysunek 5 prezentuje chwilowy przepływ mocy w węźle połączenia zespołu silnik spalinowy- generator silnika trakcyjnego i baterii. Sterowanie szeregowego układu napędowego koncentruje się na właściwym generowaniu napięcia przez generator, które to napięcie równe jest napięciu baterii.

W każdej chwili równowaga mocy w punkcie sumowania opisana jest zależnościami:

\begin{tabular}{|l|l|}
\hline $\left.\begin{array}{l}\mathrm{i}_{\mathrm{g}}-\mathrm{i}_{\mathrm{b}}=\mathrm{i}_{\mathrm{M}} \rightarrow \text { when } \mathrm{n}_{\mathrm{g}}>\mathrm{n}_{\mathrm{V}} \\
\mathrm{i}_{\mathrm{g}}+\mathrm{i}_{\mathrm{b}}=\mathrm{i}_{\mathrm{M}} \rightarrow \text { when } \mathrm{n}_{\mathrm{g}}<\mathrm{n}_{\mathrm{V}}\end{array}\right\}$ & $\begin{array}{l}\text { przyspieszanie pojazdu, } \mathrm{n}_{\mathrm{v}} \\
\mathrm{n}_{\mathrm{g}} \text { : chwilowa moc pojazdu } \\
\mathrm{i} \text { generatora }\end{array}$ \\
\hline $\mathrm{i}_{\mathrm{g}}-\mathrm{i}_{\mathrm{b}}=-\mathrm{i}_{\mathrm{M}} \rightarrow$ for $-\mathrm{n}_{\mathrm{V}}$ & $\begin{array}{l}\text { hamowanie odzyskowe } \\
\text { pojazdu }\end{array}$ \\
\hline $\mathrm{i}_{\mathrm{g}}-\mathrm{i}_{\mathrm{b}}=0$ if $\mathrm{i}_{\mathrm{M}}=0 \rightarrow$ for $\mathrm{n}_{\mathrm{V}}=0$ & postój aktywny \\
\hline $\mathrm{n}_{\mathrm{g}}=\mathrm{i}_{\mathrm{g}} \mathrm{u}_{\mathrm{g}}$ & chwilowa moc generatora \\
\hline
\end{tabular}

Moc generatora może być wyrażona jako (12), a ostatecznie jako (13),

gdzie: $\mathrm{e}_{\mathrm{g}}$ - chwilowa SEM generatora, c - stała konstrukcyjna, $\psi$ - strumień magnetyczny, $\omega_{\mathrm{g}}$ - prędkość obrotowa generatora, $\mathrm{R}_{\mathrm{g}}$ - rezystancja wewnętrzna generatora.

Prędkość obrotowa $\omega_{\mathrm{g}}$ generatora jest równa prędkości silnika spalinowego (sztywne połączenie wałów). Chwilowy moment elektromagnetyczny generatora $\left(\mathrm{m}_{\mathrm{g}}=\mathrm{c}_{1} \mathrm{i}_{\mathrm{g}} \psi\right)$ jest 
because of the efficiency). So, the ICE momentary torque, power and angular velocity can be expressed as follows:

$$
\begin{gathered}
\mathrm{m}_{\mathrm{ICE}}=\mathrm{f}\left(\mathrm{i}_{\mathrm{g}}\right)=\mathrm{c}_{2} \mathrm{i}_{\mathrm{g}} \Psi, \\
\omega_{\mathrm{ICE}}=\omega_{\mathrm{g}}=\frac{\mathrm{n}_{\mathrm{g}}+\mathrm{i}_{\mathrm{g}}^{2} \mathrm{R}_{\mathrm{g}}}{\mathrm{ci} \mathrm{i}_{\mathrm{g}} \psi}, \\
\mathrm{m}_{\mathrm{ICE}} \omega_{\mathrm{ICE}}=\mathrm{n}_{\mathrm{ICE}}
\end{gathered}
$$

If, $\psi=$ const $\rightarrow$ PM generator, $\mathrm{c}_{2} \psi=\mathrm{c}_{3}, \mathrm{c} \psi=\mathrm{c}_{4}$ and

$$
\begin{aligned}
& n_{\text {ICE }}=c_{3} i_{g}\left(\frac{n g+i_{g}^{2} R_{g}}{c_{4} i_{g}}\right) \rightarrow \\
& n_{\text {ICE }}=\frac{c_{3}}{c_{4}}\left(n_{g}-i_{g}^{2} R_{g}\right)
\end{aligned}
$$

There are the following possibilities for ICE operation: a) $n_{\mathrm{ICE}}=$ const, in this case at any moment the control system should fulfill the condition: $\mathrm{n}_{\mathrm{g}}=\mathrm{i}_{\mathrm{g}}{ }^{2} \mathrm{R}_{\mathrm{g}}$,

b) $\omega_{\mathrm{g}}=\omega_{\mathrm{ICE}}=$ const in this case at any moment the control system should fulfill the condition:

$$
\frac{n_{g}}{c_{4} i_{g}}+\frac{\dot{i}_{g}^{2} R_{g}}{c_{4} i_{g}}=\text { const }
$$

c) $m_{I C E}=$ const, in this case at any moment the control system should fulfill the condition:

$$
\mathrm{c}_{3} \mathrm{i}_{\mathrm{g}}=\text { const } \rightarrow \mathrm{i}_{\mathrm{g}}=\text { const. }
$$

The assumption $\psi=$ const can be realized when the PM generator is used. The efficiency of PM electric machines is the highest. For this reason, this type of generator is strongly recommended. The momentary values of induction motor can be worked out after similar analyses.

If the PM generator is used and the condition $\omega_{\mathrm{g}}=$ const can be fulfilled, then the result of $\mathrm{e}_{\mathrm{g}}=$ const at any moment can be obtained. In the case of other control strategies of ICE - generator, the result is $\mathrm{e}_{\mathrm{g}}=$ variable.

\section{Serial hybrid drives simulation tests}

Simulation tests were performed for three ICE control strategies: „,constant ICE rpm speed”, , ,constant ICE torque” and ,sloping rpm speed". As a result of the simulation tests modifications of all electrical and mechanical parameters of the serial hybrid drive were determined. Below the most important parameters are presented:

- operating points of ICE during driving cycle

- modification of the Battery Charge Level BCL, important parameter giving the possibility to check the battery capacity, internal resistance and electromotive force EMF adjustment

- comparison of the fuel consumption with a balanced BCL of the battery.

The results confirm proper drive parameters and control strategies adjustment of a serial hybrid drive: operating points of ICE are placed in the area of the lowest specific fuel consumption, the modification of BCL is placed in the area proporcjonalny do momentu silnika spalinowego $\left(\mathrm{m}_{\mathrm{ICE}}\right) \mathrm{i}$ $\mathrm{m}_{\mathrm{g}}=\mathrm{m}_{\mathrm{ICE}} \cdot \eta(\eta<1 \mathrm{z}$ uwzględnieniem sprawności). Zatem chwilowy moment, moc i prędkość obrotowa mogą być wyrażone jako $(14,15)$.

Występują następujące tryby pracy silnika spalinowego:

a) $n_{\text {ICE }}=$ const, $w$ tym przypadku układ sterowania powinien realizować warunek: $\mathrm{n}_{\mathrm{g}}=\mathrm{i}_{\mathrm{g}}{ }^{2} \mathrm{R}_{\mathrm{g}}$,

b) $\omega_{\mathrm{g}}=\omega_{\mathrm{ICE}}=$ const, $\mathrm{w}$ tym przypadku układ sterowania powinien realizować warunek (16).

c) $\mathrm{m}_{\mathrm{ICE}}=$ const, $\mathrm{w}$ tym przypadku układ sterowania powinien realizować warunek (17).

Warunek $\psi=$ const może być zrealizowany, gdy będzie zastosowany generator PM (generator z magnesami trwałymi). Maszyny PM mają największą sprawność i z tych powodów ten typ generatora jest szczególnie preferowany.

Jeżeli stosowany jest generator PM i może być zrealizowany warunek $\omega_{\mathrm{g}}=$ const, wówczas możliwe jest uzyskanie $\mathrm{e}_{\mathrm{g}}=$ const. $\mathrm{W}$ przypadku zastosowania innych strategii sterowania silnika spalinowego i generatora, rezultatem jest $\mathrm{e}_{\mathrm{g}}=$ variable.

\section{Testy symulacyjne szeregowych napędów hybrydowych}

Dla przyjętych parametrów pojazdu wykonano badania symulacyjne dla trzech strategii sterowania silnikiem spalinowym: „stała prędkość silnika”, „stały moment silnika” i „narastająca prędkość silnika”. W wyniku badań symulacyjnych uzyskano przebiegi w funkcji czasu wszystkich, głównych parametrów mechanicznych i elektrycznych szeregowego, hybrydowego układu napędowego. Poniżej przedstawiono najciekawsze, z punktu widzenia efektywności układu napędowego, wyniki, tj.:

- punkty pracy silnika spalinowego podczas realizacji cyklu jazdy

- przebieg stopnia naładowania baterii SOC, krytyczny parametr, pozwalający na ocenę prawidłowości doboru parametrów baterii (pojemność) i zakresu jej pracy (powiązanego ze zmianą rezystancji wewnętrznej i siły elektromotorycznej SEM)

- porównanie zużycia paliwa w warunkach zbilansowanego poziomu naładowania baterii na początku i na końcu cyklu jazdy.

Uzyskane wyniki świadczą o prawidłowości doboru parametrów i strategii sterowania szeregowym, hybrydowym układem napędowym: punkty pracy silnika spalinowego mieszczą się w obszarach minimalnego jednostkowego zużycia paliwa, stopień naładowania baterii SOC waha się w zakresach, w których rezystancja wewnętrzna jest niska, a głębokość rozładowania (mierzona jako $\triangle \mathrm{SOC}$ ) pozwala na zachowanie bezpiecznego zapasu energii dyspozycyjnej akumulatorów. W odniesieniu do napędu hybrydowego, według wyników badań symulacyjnych, uzyskano mniejsze $\mathrm{w}$ porównaniu $\mathrm{z}$ napędem klasycznym zużycie paliwa. 


\begin{tabular}{|c|c|c|c|c|}
\hline \multicolumn{2}{|l|}{ Vehicle data/Dane pojazdu } & \multirow{2}{*}{$\begin{array}{l}\text { Battery/akumulator } \\
\mathrm{NiMH} \\
\text { Nominal capacity/ } \\
\text { nominalna pojemnośc: } 144 \mathrm{~A} \cdot \mathrm{h} \\
\begin{array}{l}\text { Nominal voltage/ } \\
\text { nominalne napięcie: } \quad 300 \mathrm{~V}\end{array}\end{array}$} & \multicolumn{2}{|l|}{ Traction motor/silnik napędowy } \\
\hline \multirow{3}{*}{$\begin{array}{l}\text { Mass/masa: } \\
\text { Front area/pow. czołowa: } \\
\text { Drag coeff./ } \\
\text { wsp. oporów powietrza: } \\
\text { Rolling friction coeff./ } \\
\text { wsp. oporów toczenia: } \\
\text { Tyre rolling radius// } \\
\text { promień dynamiczny koła: }\end{array}$} & $\begin{array}{l}15000 \mathrm{~kg} \\
6.92 \mathrm{~m}^{2} \\
0.55 \\
0.01\end{array}$ & & $\begin{array}{l}\text { Number of poles/liczba biegunów } \\
\mathrm{PM} \text { flux/strumień indukcji magnetycznej silnika PM } \\
\text { Coils inductance L/indukcyjność cewki } \\
\text { Coils resistance R/oporność cewki } \\
\text { Max torque/maksymalny moment obrotowy } \\
\text { Max speed/maksymalna prędkość }\end{array}$ & $\begin{array}{l}\text { p } 24 \\
0.05775 \mathrm{~Wb} \\
0.000076 \mathrm{H} \\
0.04 \Omega \\
275 \mathrm{~N} \cdot \mathrm{m} \\
8500 \mathrm{rpm}\end{array}$ \\
\hline & & ICE/silnik spalinowy & Generator/pradnica & \\
\hline & & Diesel $1180 \mathrm{ccm}$ JDT & $\begin{array}{l}\text { Number of poles/liczba biegunów } \\
\text { PM flux/strumień indukcji magnetycznej silnika PM } \\
\text { Coils inductance L/indukcyjność cewki } \\
\text { Coils resistance R/oporność cewki }\end{array}$ & $\begin{array}{l}\text { p } 24 \\
0.10311 \mathrm{~Wb} \\
0.000248 \mathrm{H} \\
0.04 \Omega\end{array}$ \\
\hline
\end{tabular}

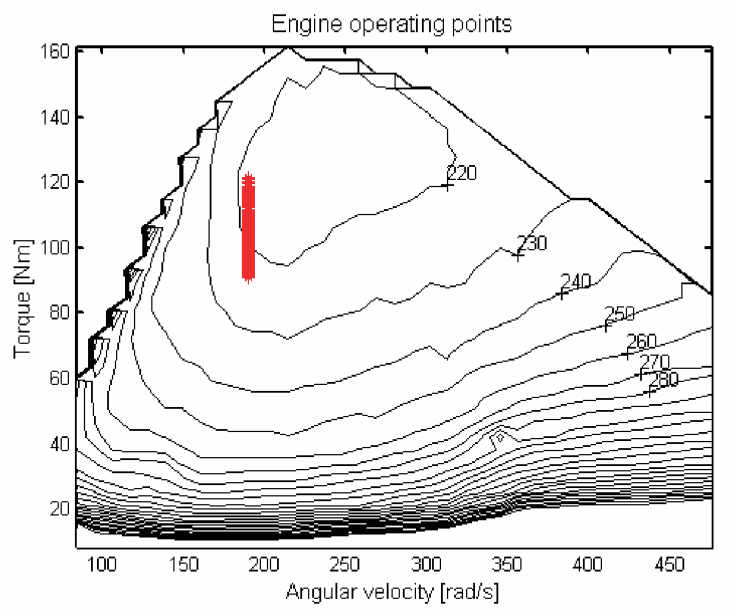

Fig. 6. Map of "constant speed" operating engine. The engine operates in the area of the lowest specific fuel consumption

Rys. 6. Mapa silnika spalinowego z punktami pracy podczas realizacji strategii „stała prędkość”. Punkty pracy silnika spalinowego mieszcza się w obszarze minimalnego jednostkowego zużycia paliwa

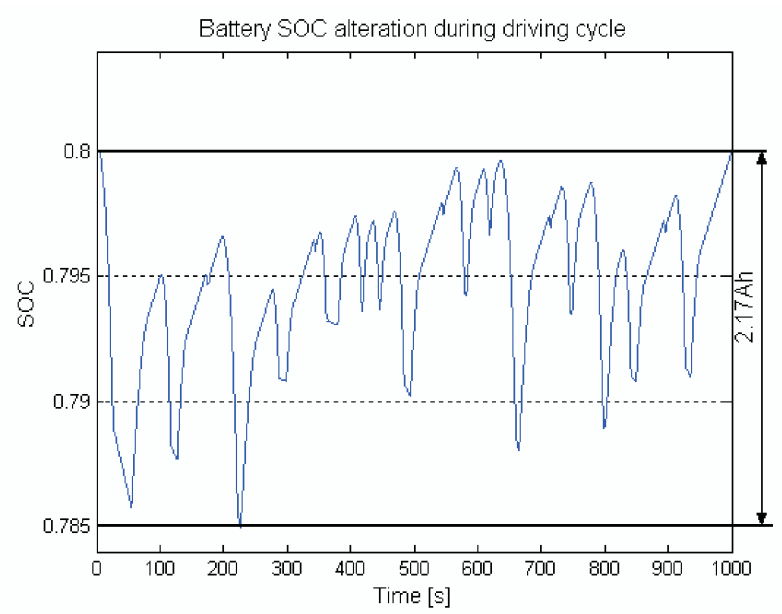

Fig. 7. Battery BCL modification during driving cycle for "constant speed" strategy. The battery operates in the area of low internal resistance and high efficiency. The battery is balanced (exactly the same initial and terminal $\mathrm{BCL}=0.8)$ with good depth of discharge level $(2.17 \mathrm{~A} \cdot \mathrm{h})$

Rys. 7. Stan naładowania baterii BCL podczas realizacji strategii , stała prędkość". Bateria pracuje w obszarze niskiej rezystancji wewnętrznej, więc dużej sprawności. Bateria jest zbalansowana (ten sam poziom naładowania baterii $B C L=0,8$ na poczatku i na końcu cyklu jazdy), przy dobrym poziomie głębokości rozładowania $(2,17 \mathrm{~A} \cdot h)$

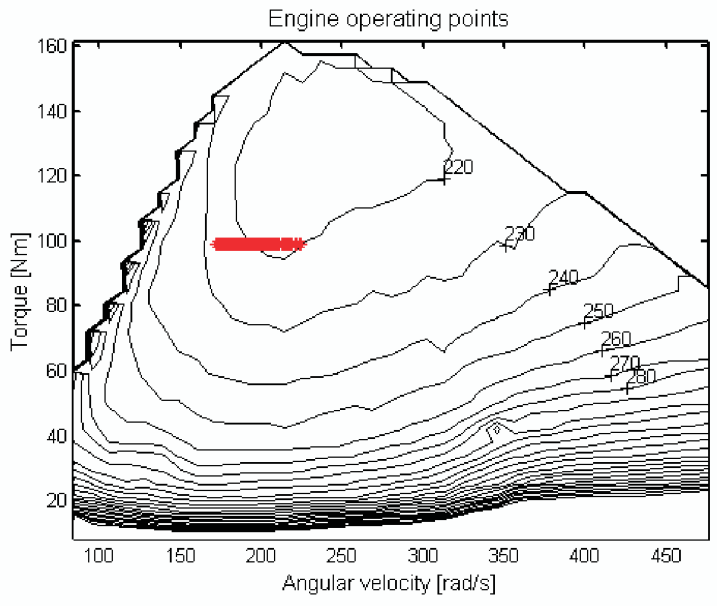

Fig. 8. Map of "constant torque" operating engine. The engine operates in the area of the lowest specific fuel consumption

Rys. 8. Mapa silnika spalinowego z punktami pracy podczas realizacji strategii , staly moment”. Punkty pracy silnika spalinowego mieszcza sie w obszarze minimalnego jednostkowego zużycia paliwa

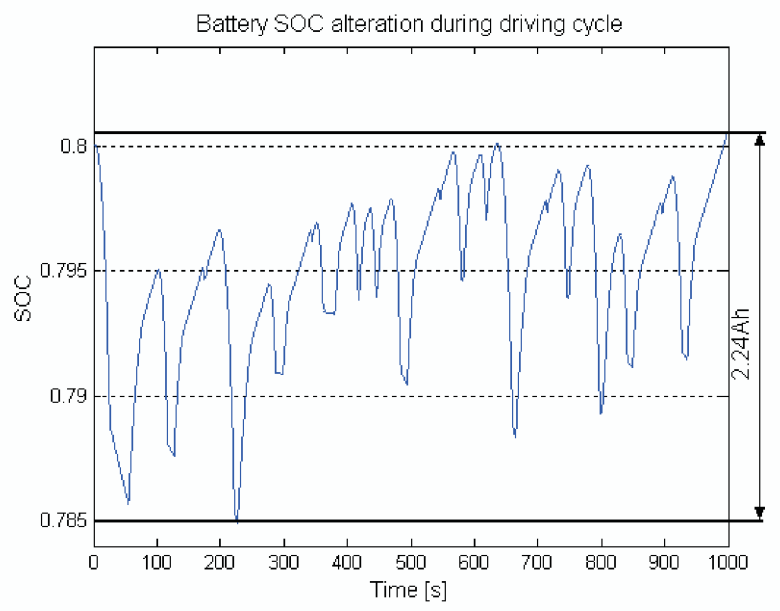

Fig. 9. Battery BCL alteration during driving cycle for "constant torque". The battery operates in the area of low internal resistance and high efficiency. The battery is balanced (almost the same initial and terminal

$\mathrm{BCL}=0.8)$ with good depth of discharge level $(2.24 \mathrm{~A} \cdot \mathrm{h})$

Rys. 9. Stan naladowania baterii BCL podczas realizacji strategii ,staty moment". Bateria pracuje w obszarze niskiej rezystancji wewnętrznej, więc dużej sprawności. Bateria jest zbalansowana (prawie ten sam poziom natadowania baterii $B C L=0,8$ na początku i na końcu cyklu jazdy), przy dobrym poziomie głębokości rozładowania $(2,24 \mathrm{~A} \cdot h)$ 


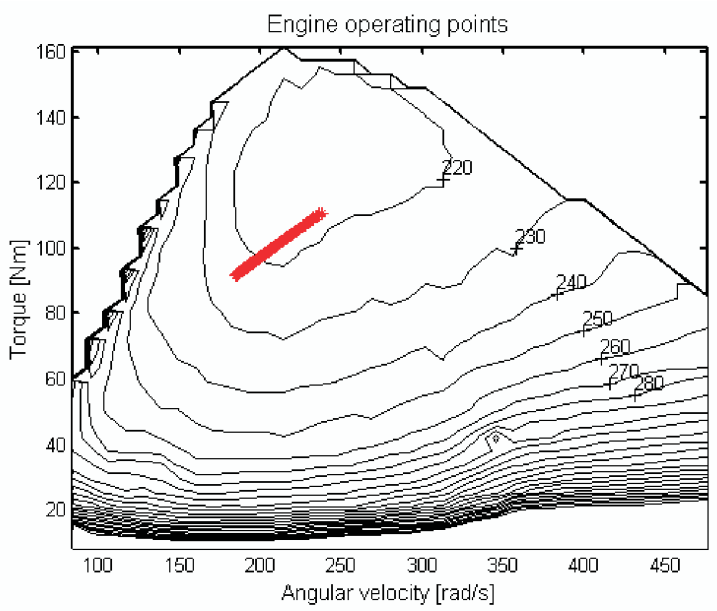

Fig. 10. Map of "sloping speed" operating engine. The engine operates in the area of the lowest specific fuel consumption

Rys. 10. Mapa silnika spalinowego z punktami pracy podczas realizacji strategii ,, narastająca prędkość”. Punkty pracy silnika spalinowego mieszcza się w obszarze minimalnego jednostkowego zużycia paliwa

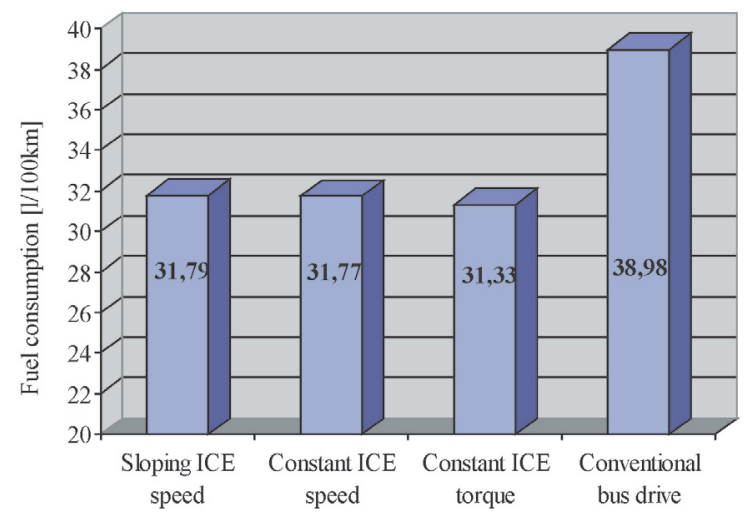

Fig. 12. Comparison of the fuel consumption $\left(\mathrm{dm}^{3} / 100 \mathrm{~km}\right)$ of three control strategies in serial hybrid bus drive and a conventional drive Rys. 12. Porównanie zużycia paliwa $\left(\mathrm{dm}^{3} / 100 \mathrm{~km}\right)$ dla trzech strategii sterowania szeregowego napędu hybrydowego oraz klasycznego dla autobusu

of low internal resistance, and depth of discharge (calculated as $\triangle \mathrm{BCL}$ ) is limited. According to the obtained results, the fuel consumption in the case of serial hybrid drive is lower than in the case of a conventional drive.

\section{Compact Hybrid Planetary Transmission Drive (CHPTD)}

The layout scheme of CHPTD (patented by A. Szumanowski) showed in Fig. 13 and 14 presents the control network necessary for proper CHPTD operation.

This drive architecture is characterized by the following shaft connections: ICE via a mechanical reducer and a clutch-brake system is linked with

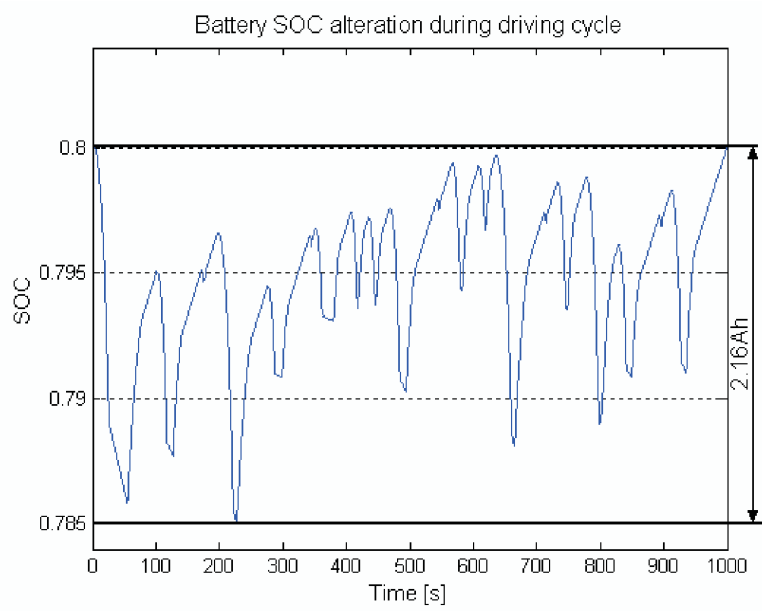

Fig. 11. Battery BCL alteration during driving cycle for "sloping speed". The battery operates in the area of low internal resistance and high efficiency. The battery is balanced (exactly the same initial and terminal $\mathrm{BCL}=0.8)$ with good depth of discharge level $(2.16 \mathrm{~A} \cdot \mathrm{h})$

Rys. 11. Stan naładowania baterii BCL podczas realizacji strategii „,narastająca prędkość”. Bateria pracuje w obszarze niskiej rezystancji wewnętrznej, więc dużej sprawności. Bateria jest zbalansowana (ten sam poziom naładowania baterii $B C L=0,8$ na początku i na końcu cyklu

jazdy), przy dobrym poziomie głębokości rozładowania $(2,16 \mathrm{~A} \cdot \mathrm{h})$

\section{Kompaktowy napęd hybrydowy z przekladnią planetarną (CHPTD)}

Schemat blokowy napędu hybrydowego z przekładnią planetarną CHPTD (opatentowany przez A. Szumanowskiego) pokazano na rys. 13 i 14, łącznie z niezbędnymi sygnałami sterowania.

Struktura układu napędowego scharakteryzowana jest następującym połączeniem wałów: silnik spalinowy poprzez reduktor i system sprzęgło/hamulec połączony jest z kołem słonecznym przekładni planetarnej (koło 1 na rys. 15). Silnik elektryczny połączony jest z kołem koronowym (koło 2).

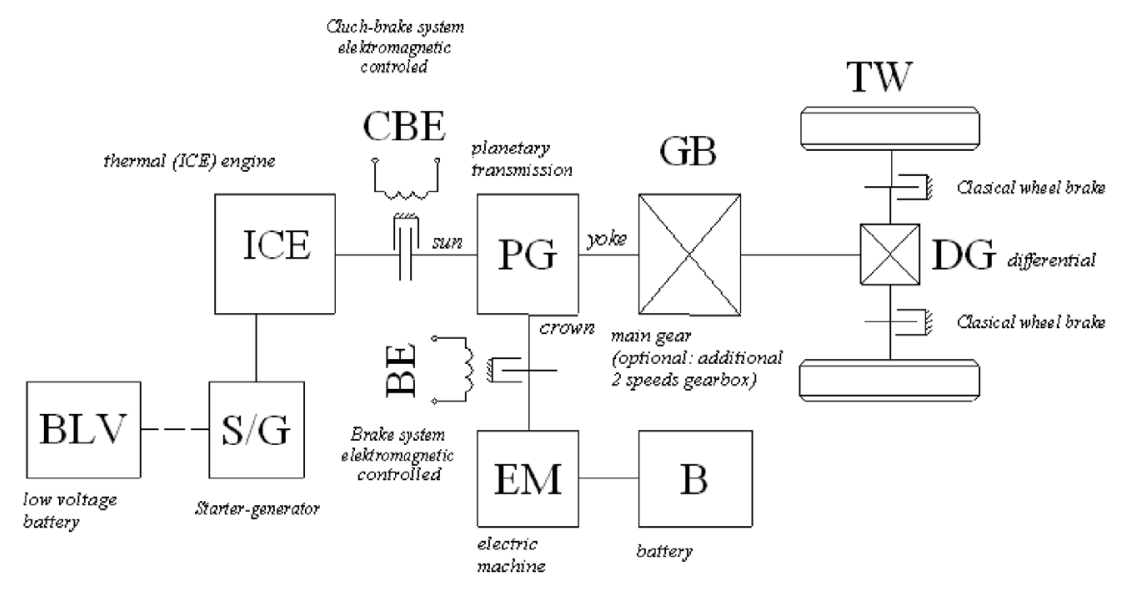

Fig. 13. Layout of compact hybrid drives with planetary transmission - block schematics

Rys. 13. Schemat blokowy napędu hybrydowego z przekladnia planetarna CHPTD. Thumaczenie skrótów: ICE - silnik spalinowy, BLV-bateria rozruchowa, CBE - uktad sprzęgło/hamulec, $P G$ - przekładnia planetarna, EM - elektryczny silnik trakcyjny, B - bateria trakcyjna, GB - przekładnia, $D G$ - mechanizm różnicowy, $T W$ - koła jezdne 
a planetary sun wheel (wheel 1 of Fig. 15). Electric machine is connected with the crown wheel (wheel 2). Planetary yoke wheel (wheel 3) transmits the sum (with positive or negative sign depending on the drive operating mode) of power generated by the engine and the motor through the main and differential gear set to the traction wheels.

This drive applied in the vehicle can operate in two modes during vehicle start (Fig. 16):

- hybrid acceleration

- pure electric acceleration

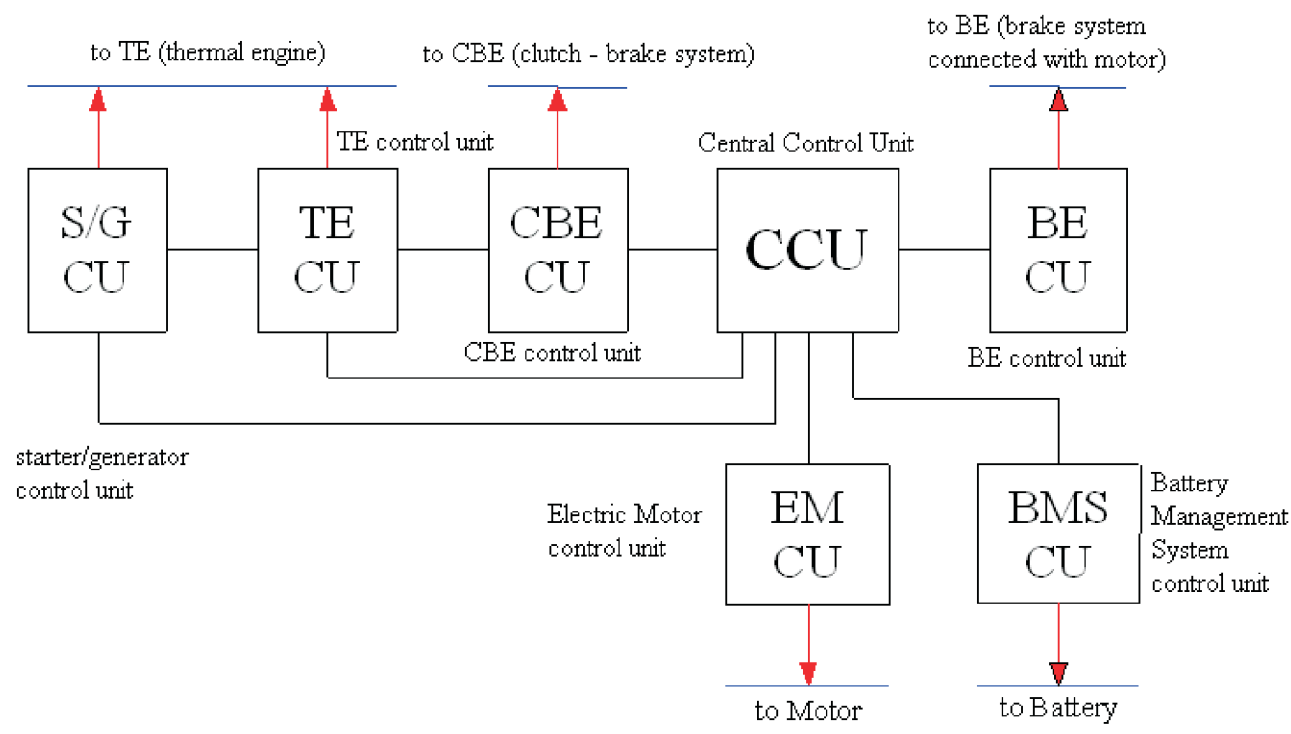

Fig. 14. Layout of compact hybrid drives with planetary transmission - control system block

Rys. 14. Schemat blokowy napędu hybrydowego z przekładnia planetarna - sygnaty sterujace. Ttumaczenie skrótów: SGCU - sterownik starter/generatora, TECU - sterownik silnika spalinowego, CBECU - sterownik sprzegła/ hamulca, CCU - sterownik centralny, EMCU - sterownik silnika elektrycznego, BMSCU - sterownik systemu kondycjonowania baterii

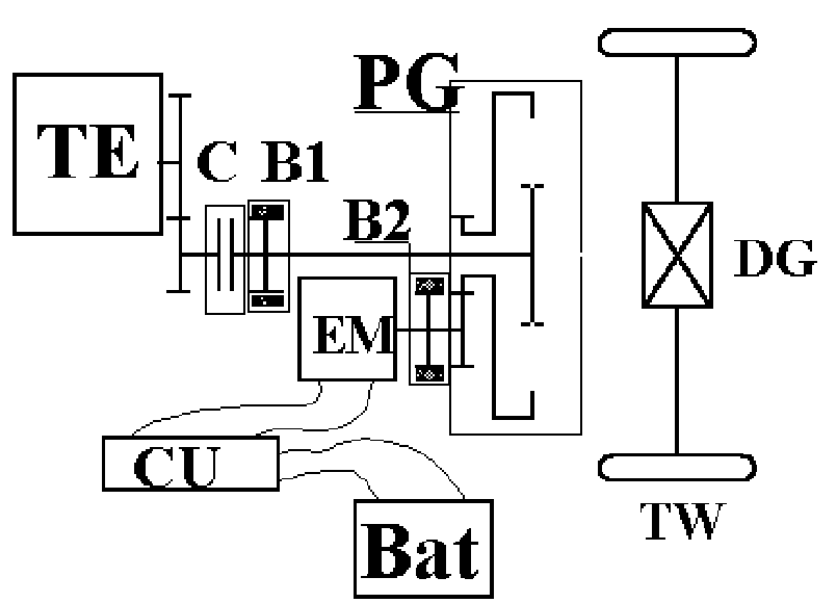

TE - Thermal (Internal Combustion) Engine, PG - Two Degrees of Freedom Planetary Gear Set, EM - Motor/Generator, Bat - Battery, C - Clutch, B1, B2 - Shafts Brakes, DG - Main Differential Gear, TW - Traction Wheels, CU - Control Unit, 1 - sun wheel, 2 - crown wheel, 3 - yoke
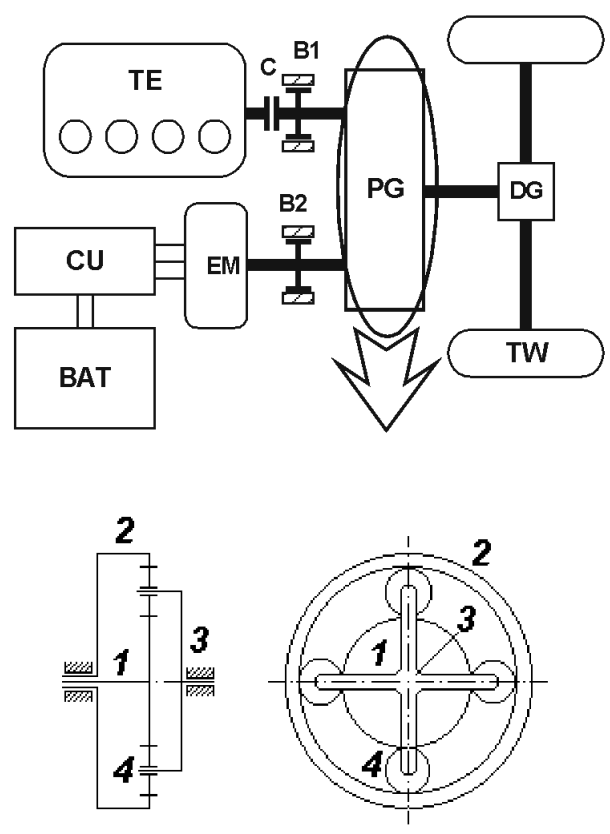

Fig. 15. CHPTD kinetic connections

Rys. 15. Schemat napędu hybrydowego z przekładnia planetarna. Tłumaczenie skrótów jak na rys. 13

\section{Comparison of simulation results of the CHPTD with $500 \mathrm{~V} 36 \mathrm{~A} \cdot \mathrm{h}$ Li-ion battery and $500 \mathrm{~V} 80 \mathrm{~A} \cdot \mathrm{h}$ NiMH battery}

The following comparison of the simulation results is about CHPTD with $500 \mathrm{~V} 36 \mathrm{~A} \cdot \mathrm{h}$ Li-ion battery and $500 \mathrm{~V} 80 \mathrm{~A} \cdot \mathrm{h} \mathrm{NiMH}$ battery. In order to get the comparable
Jarzmo przekładni planetarnej (koło 3) transmituje przez przekładnię główną i mechanizm różnicowy sumę mocy, generowaną przez silnik elektryczny i spalinowy.

Zaprezentowany układ napędowy może pracować w dwóch trybach podczas rozpoczynania jazdy (rys. 16):

- hybrydowe przyspieszanie

- przyspieszanie "czysto" elektryczne. 

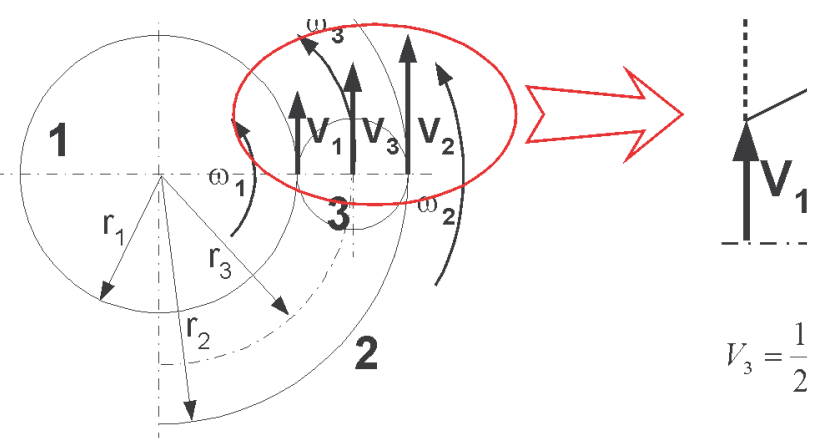

Fig. 16. Speed vector relations respectively to three rotating shafts of planetary gearbox

Rys. 16. Zależności pomiędzy wektorami prędkości liniowych powiąanych z prędkościami obrotowymi wałów przekładni planetarnej

results, we tried to keep the same main parameters or similar of the CHPTD and only adjust some parameters of the battery pack.

The nominal energy of the NiMH battery pack is $40 \mathrm{~kW} \cdot \mathrm{h}$, which is two times more than the Li-ion battery pack (18 $\mathrm{kW} \cdot \mathrm{h})$. However, the fuel consumption of the engine with the Li-ion battery pack is lower than in the case of the NiMH battery pack. The reason is that the internal resistance value of $500 \mathrm{~V} 80 \mathrm{~A} \cdot \mathrm{h}$ NiMH battery pack is about $0.475 \Omega(\mathrm{k}=0.8)$, which is about 3 times of $0.158 \Omega(\mathrm{BCL}=0.55)$, the internal resistance value of the $500 \mathrm{~V} 36 \mathrm{~A} \cdot \mathrm{h}$ Li-ion battery pack.

Comparison of the main parameters of CHPTD for 500 V battery pack.

\begin{tabular}{|c|c|c|}
\hline Battery/akumulator & $\begin{array}{l}500 \mathrm{~V} 36 \mathrm{~A} \cdot \mathrm{h} \\
\text { Li-ion battery } \\
\text { pack }\end{array}$ & $\begin{array}{l}500 \mathrm{~V} 80 \mathrm{~A} \cdot \mathrm{h} \\
\mathrm{NiMH} \text { battery } \\
\text { pack }\end{array}$ \\
\hline $\begin{array}{l}\text { Nominal energy of battery pack/ } \\
\text { nominalna energia akumulatorów }\end{array}$ & $18 \mathrm{~kW} \cdot \mathrm{h}$ & $40 \mathrm{~kW} \cdot \mathrm{h}$ \\
\hline $\begin{array}{l}\text { Main gear - differential ratio/ } \\
\text { przełożenie przekładni głównej }\end{array}$ & 4.98 & 4.88 \\
\hline $\begin{array}{l}\text { The basic planetary gear ratio/ } \\
\text { przetożenie przektadni planetarnej }\end{array}$ & 2.87 & 2.87 \\
\hline $\begin{array}{l}\text { Reducer ratio between PM motor } \\
\text { and planetary gear/przelożenie } \\
\text { reduktora }\end{array}$ & 4.8 & 4.8 \\
\hline $\begin{array}{l}\text { Reducer ratio between engine } \\
\text { and planetary gear/przełożenie } \\
\text { reduktora }\end{array}$ & $1.46 \times 1.25$ & $1.46 \times 1.24$ \\
\hline Vehicle mass/masa pojazdu & $15,000 \mathrm{~kg}$ & $15,000 \mathrm{~kg}$ \\
\hline Vehicle front area/pow. czolowa & $6.92 \mathrm{~m}^{2}$ & $6.92 \mathrm{~m}^{2}$ \\
\hline Drag coefficient $\mathrm{c}_{\mathrm{x}}$ /współ. oporów $c_{x}$ & 0.55 & 0.55 \\
\hline $\begin{array}{l}\text { Dynamic tyre radius index } \mathrm{r}_{\mathrm{dyn}} / \\
\text { dynamiczny promień koła } r_{d y n}\end{array}$ & $0.51 \mathrm{~m}$ & $0.51 \mathrm{~m}$ \\
\hline $\begin{array}{l}\text { Nominal voltage of battery pack/ } \\
\text { nominalne napięcie akumulatorów }\end{array}$ & $500 \mathrm{~V}$ & $500 \mathrm{~V}$ \\
\hline $\begin{array}{l}\text { Nominal battery capacity/nomi- } \\
\text { nalna pojemność akumulatorów }\end{array}$ & $36 \mathrm{~A} \cdot \mathrm{h}$ & $80 \mathrm{~A} \cdot \mathrm{h}$ \\
\hline Fuel consumption/zużycie paliwa & $24.96 \mathrm{l} / 100 \mathrm{~km}$ & $26.06 \mathrm{l} / 100 \mathrm{~km}$ \\
\hline Diesel engine/silnik $Z S$ & $7800 \mathrm{cc}$ & $7800 \mathrm{cc}$ \\
\hline $\begin{array}{l}\text { Warsaw driving cycle - top speed/ } \\
\text { maks. prędkość w teście warszawskim }\end{array}$ & $50 \mathrm{~km} / \mathrm{h}$ & $50 \mathrm{~km} / \mathrm{h}$ \\
\hline $\begin{array}{l}\text { Engine control strategy parame- } \\
\text { ters/parametry sterowania }\end{array}$ & $\begin{array}{l}{\left[\begin{array}{llllll}-10 & 0 & 0 & 7 & 8 & 30\end{array}\right]} \\
{\left[\begin{array}{lllll}0 & 0 & 0 & 172 & 410\end{array}\right]}\end{array}$ & 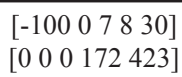 \\
\hline
\end{tabular}

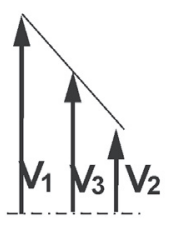

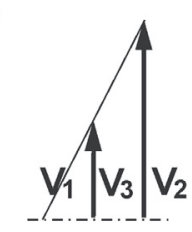

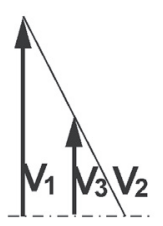

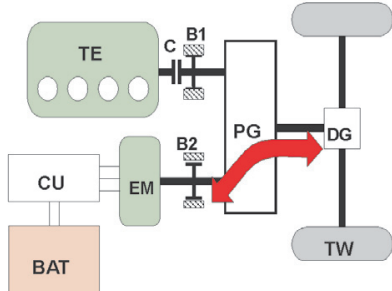
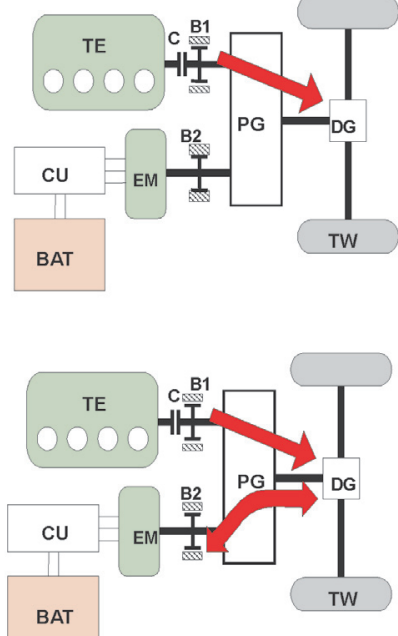

Fig. 17. Brake system operation and energy flow corresponding to a) pure electric, b) pure ICE, c) hybrid

Rys. 17. Działanie systemu hamulców i przeplywy energii odpowiadajace trybowi pracy: a) ,,czysto” elektrycznemu, b) ,,czysto” spalinowemu c) hybrydowemu

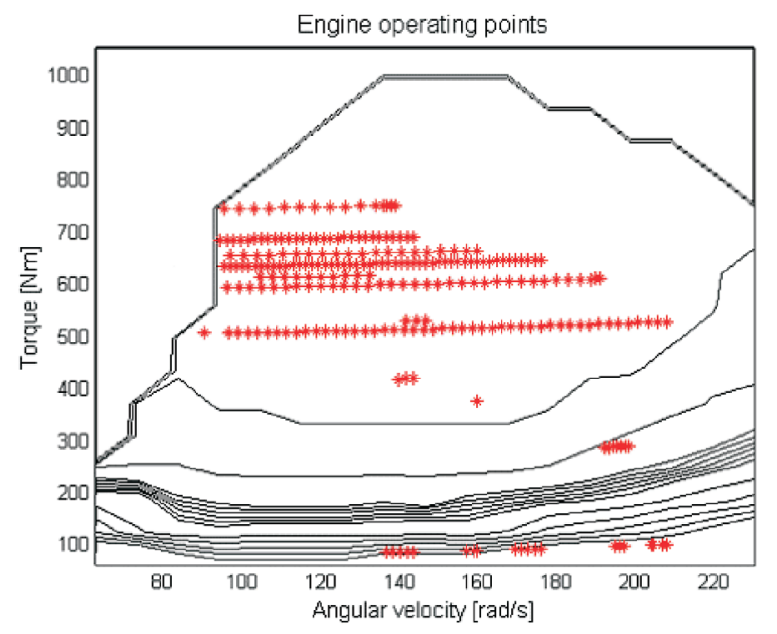

Fig. 18. Engine operating points of CHPTD with the $500 \mathrm{~V} \mathrm{Li-ion}$ battery. The engine operates mainly in the area of the lowest specific fuel consumption

Rys. 18. Punkty pracy silnika dla układu z przekładnia planetarna i bateria $500 \mathrm{~V}$ Li-ion. Punkty pracy silnika spalinowego mieszcza się najczęściej w obszarze minimalnego jednostkowego zużycia paliwa

6. Porównanie wyników badań symulacyjnych napędu hybrydowego $\mathrm{z}$ przekładnią planetarną CHPTD z baterią $500 \mathrm{~V} 36 \mathrm{~A} \cdot \mathrm{h}$ Li-ion i $500 \mathrm{~V}$ $80 \mathrm{~A} \cdot h \mathrm{~h}$ NiMH

Porównano wyniki badań symulacyjnych napędu hybrydowego z przekładnią planetarną CHPTD z baterią $500 \mathrm{~V} 36 \mathrm{~A} \cdot \mathrm{h}$ 


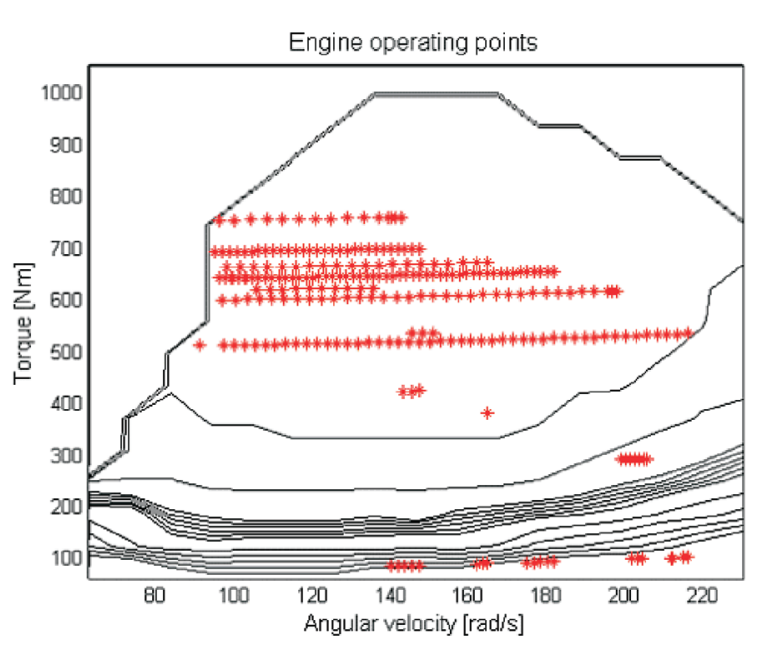

Fig. 19. Engine operating points of CHPTD with the $500 \mathrm{~V}$ NiMH battery. The engine operates mainly in the area of the lowest specific fuel consumption

Rys. 19. Punkty pracy silnika dla uktadu z przektadnia planetarna i bateria $500 \mathrm{~V}$ NiMH. Punkty pracy silnika spalinowego mieszcza się najczęściej w obszarze minimalnego jednostkowego zużycia paliwa

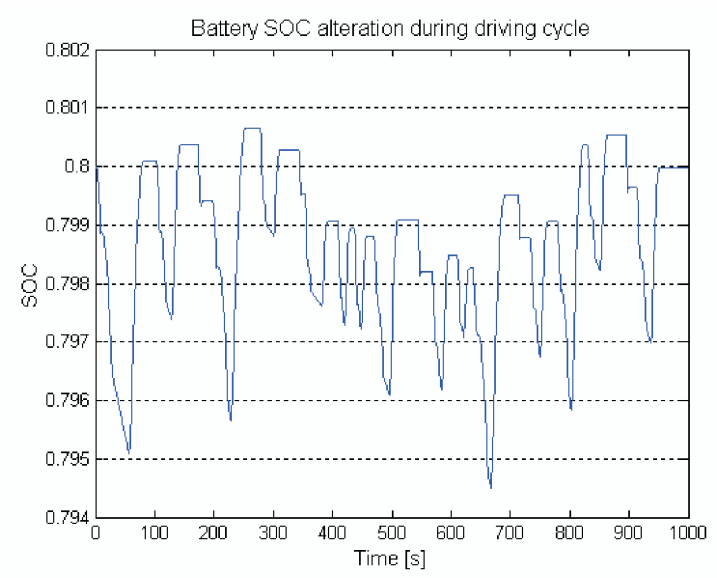

Fig. 21. Battery BCL alteration of CHPTD with the $500 \mathrm{~V}$ NiMH battery. The battery operates in the area of low internal resistance and high efficiency. The battery is balanced (exactly the same initial and terminal $\mathrm{BCL}=0.8$ )

Rys. 21. Stan naładowania baterii BCL dla układu z przekładnia planetarna i bateria $500 \mathrm{VNiMH}$. Bateria pracuje w obszarze niskiej rezystancji wewnętrznej, więc dużej sprawności. Bateria jest zbalansowana (ten sam poziom naładowania baterii $B C L=0,8$ na poczatku i na końcu cyklu jazdy)

\section{Conclusions}

According to the simulation results, some conclusions are as follows:

1. In the case of serial hybrid drives:

- the assumed control based on "constant torque" and "constant speed" with the limitation of generator angular velocity permits to obtain a proper ICE - generator set operation

- the smallest modification of power, torque and velocity of ICE - generator set confirmed the theoretical analyses

- the presented method is necessary for the design of serial hybrid drives

- these promising results of fuel consumption for gasoline ICE allow to expect similar advantages when $\mathrm{CNG}$ or LNG engines are used
Li-ion i $500 \mathrm{~V} 80$ A·h NiMH. Aby uzyskać zbliżone warunki porównawcze, utrzymano te same główne parametry układu napędowego, zmieniając nieznacznie jedynie parametry baterii.

Energia nominalna baterii NiMH wynosi $40 \mathrm{~kW} \cdot \mathrm{h}$, prawie dwukrotnie więcej niż baterii Li-ion $18 \mathrm{~kW} \cdot \mathrm{h}$. Mimo to zużycie paliwa w układzie z baterią Li-ion jest mniejsze. Przyczyną jest prawie 3-krotnie mniejsza rezystancja wewnętrzna baterii Li-ion, wynosząca dla całego zestawu $0,158 \Omega(\mathrm{SOC}=0,55)$, w porównaniu do $0,475 \Omega(\mathrm{k}=0,8)$ dla zestawu NiMH.

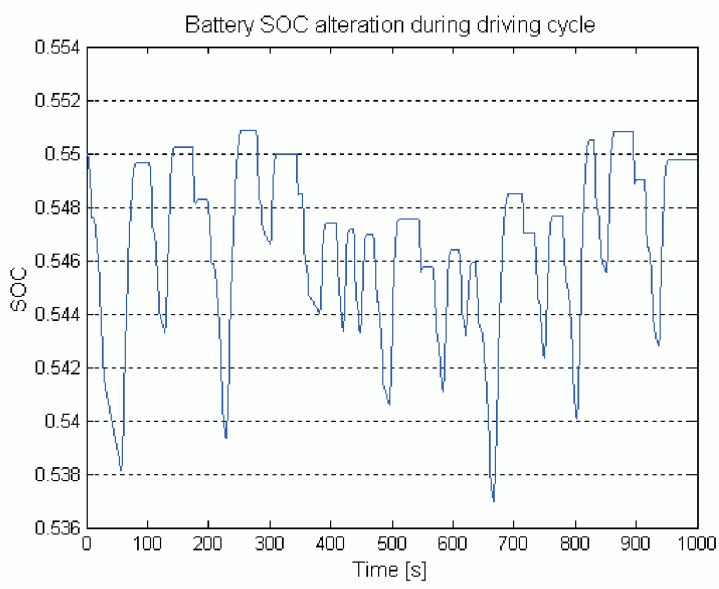

Fig. 20. Battery BCL alteration of CHPTD with the $500 \mathrm{~V}$ Li-ion battery.

The battery operates in the area of low internal resistance and high efficiency. The battery is balanced (exactly the same initial and terminal $\mathrm{BCL}=0.55)$

Rys. 20. Stan naładowania baterii BCL dla uktadu z przektadnia planetarna i bateria $500 \mathrm{~V}$ Li ion. Bateria pracuje w obszarze niskiej rezystancji wewnętrznej, więc dużej sprawności. Bateria jest zbalansowana (ten sam poziom naładowania baterii $B C L=0,55$ na poczatku i na końcu cyklu jazdy)

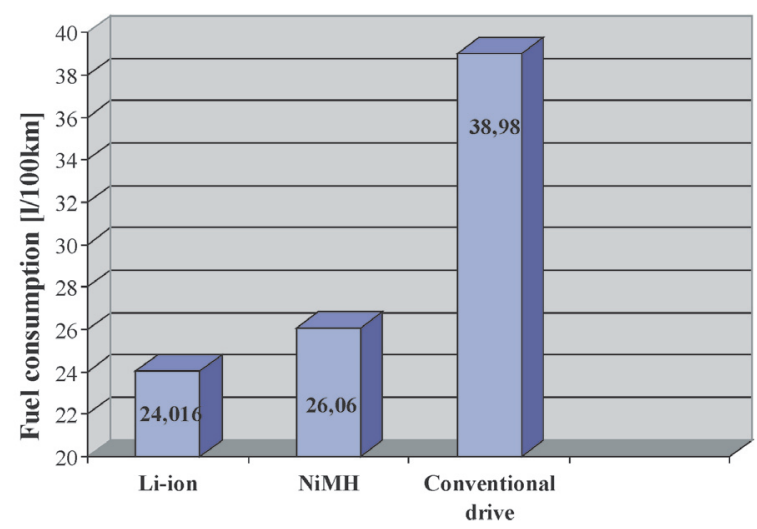

Fig. 22. Comparison of the fuel consumption $\left(\mathrm{dm}^{3} / 100 \mathrm{~km}\right)$ for CHPTD equipped two types of battery pack

Rys. 22. Porównanie zużycia paliwa $\left(\mathrm{dm}^{3} / 100 \mathrm{~km}\right)$ dla układu z przekładnia planetarna wyposażonego $w$ dwa typy baterii

\section{Wnioski}

Na podstawie wyników badań symulacyjnych sformułowano następujące wnioski:

1. Dla napędu hybrydowego szeregowego:

- przyjęcie strategii sterowania "stałego momentu” i ,stałej prędkości” z ograniczeniem prędkości obrotowej generatora pozwala uzyskać właściwe warunki pracy zespołu silnik spalinowy-generator 
- the use of a small diesel engine in a serial hybrid drive equipped with a battery pack as high capacity causes ICE operation in area of relatively high torque low - because noise should be reduced - angular velocity of engine shaft. This means the engine operating points are near or in majority, inside the area of its highest efficiency. Anyway, the fuel consumption is only about $7 \mathrm{dm}^{3} / 100 \mathrm{~km}$ less than in the conventional diesel bus drive. It results from the serial drive architecture and the demand for battery balance.

2. In the case of CHPTD:

- the power of ICE must be adjusted to assumed vehicle speed. Contrary to "serial drive", parallel CHPTD gives possibilities to drive using only ICE. This is the advantage of this type of hybrid drive because if under high constant speed driving for a long time (e.g. motorway driving) hybrid drive is not useful. Of course it is used for the acceleration and regenerative braking at all times

- despite the operating points of ICE operation are spread (but only in the area of minimum fuel consumption), the fuel consumption is much lower than in the case of serial hybrid drives

- the use of planetary transmission gives a more flexible torque distribution providing the most effective ICE operation

- CHPTD is more compact, lighter (only one electric motor) than the serial hybrid drive

- the CHPTD is very profitable particularly in the case of city buses.

From a general point of view, the proposed method for hybrid drive fitted with ICE is a very good tool. A computer simulation based on a properly developed hybrid powertrain components modeling, allows an optimal component parameters adjustment and the adjustment of its dynamic characteristics. ICE operation can be analyzed and properly designed. Finally, it's necessary to remark that the difference of ICE fuel consumption using its mathematical model and ICE map is really small (only a few per cent). It's not at all strange because an ICE map is based on a bench-test and obtained by proper modelling.

\section{Bibliography/Literatura}

[1] Szumanowski A.: Hybrid Electric Vehicle Drives Design - Edition Based On Urban Buses, Monographbook, ITE, Warszawa 2006.

[2] Szumanowski A.: Fundamentals of Hybrid Vehicle Drives, Monographbook, ITE, Warszawa 2000.

[3] Gear C.W.: Simulations Numerical Solution of Differential Algebraic Equations, IEEE Trans. 18/1971.

[4] Gear C.W.: DIFSUB for the Solution of Ordinary Differential Equations, CACM 14/1972.

[5] Szumanowski A., Hajduga A., Piórkowski P.: Proper adjustment of combustion engine and induction motor in hybrid vehicles drive, EVS15, Bruksela 1998.

[6] Szumanowski A., Hajduga A., Piórkowski P.: Evaluation of Efficiency Alterations in Hybrid and Electric Vehicles Drives. Proceeding of Advanced Propulsion Systems GPC, Detroit 1998.

[7] Szumanowski A., Chang Yuhua, Piórkowski P.: Analysis of Different Control Strategies and Operating Modes of Compact Hybrid Planetary Transmission Drive, 2005 IEEE Vehicle Power and Propulsion (VPP) Conference (Sep.7-9, 2005, Illinois Institute of Technology) in Chicago, Illinois, USA.
- uzyskano najmniejszą zmienność mocy, momentu i prędkości silnika spalinowego - potwierdzoną teoretycznie

- zaprezentowana metoda sterowania jest niezbędna do projektowania szeregowych napędów hybrydowych

- uzyskane dla silnika benzynowego wyniki zużycia paliwa pozwalają oczekiwać podobnych rezultatów dla silników zasilanych CNG i LNG

- zastosowanie małego silnika o ZS w szeregowym napędzie hybrydowym wyposażonym w zestaw baterii o wysokiej pojemności pozwala na pracę silnika spalinowego ze stosunkowo wysokim momentem przy małej prędkości wału silnika, co ogranicza emisję hałasu. Jednocześnie punkt pracy silnika można umiejscowić w pobliżu obszaru najmniejszego jednostkowego zużycia paliwa. Zużycie paliwa wyniosło o około $7 \mathrm{dm}^{3} / 100 \mathrm{~km}$ mniej niż w przypadku konwencjonalnego napędu autobusu z silnikiem o ZS.

2. W przypadku napędu CHPTD:

- moc silnika spalinowego musi być dostosowana do prędkości pojazdu. W odróżnieniu od napędu szeregowego, napęd CHPTD umożliwia jazdę z użyciem wyłącznie silnika spalinowego. Jest to ważna cecha tego napędu, gdyż przy długotrwałej jeździe z dużą prędkością hybrydowy tryb jazdy jest nieefektywny. Oczywiście ten tryb jest wykorzystywany w przypadku przyspieszania i hamowania odzyskowego

- pomimo że punkty pracy silnika spalinowego są rozproszone (ale tylko w obszarze minimalnego zużycia paliwa), zużycie paliwa jest znacznie mniejsze niż w przypadku szeregowego napędu hybrydowego

- zastosowanie przekładni planetarnej umożliwia elastyczne dostosowanie dystrybucji momentu trakcyjnego, pozwalającej na bardziej efektywną pracę silnika spalinowego

- napęd CHPTD jest bardziej zwarty i lekki niż szeregowy napęd hybrydowy (tylko jedna maszyna elektryczna)

- napęd CHPTD jest szczególnie efektywny zwłaszcza w napędach miejskich autobusów.

Zaproponowana metoda jest bardzo dobrym narzędziem projektowania hybrydowych układów napędowych z silnikiem spalinowym. Badania symulacyjne, bazujące na opracowanych modelach komponentów napędu, pozwalają na właściwy dobór ich parametrów i charakterystyk dynamicznych. Przede wszystkim można właściwie dostosować działanie silnika spalinowego do wymagań napędu hybrydowego. Należy również podkreślić, że różnica zużycia paliwa uzyskana z modelu matematycznego silnika i zjego map jest bardzo mała (rzędu kilku procent). Jest to efektem tego, że mapy chwilowego zużycia paliwa bazują na wynikach badań laboratoryjnych.

\section{Artykut recenzowany}

Prof. Antoni Szumanowski, DSc., DEng. - Professor in the Faculty of Automotive and Construction Machinery Engineering at Warsaw University of Technology.

Prof. dr hab. inż. Antoni Szumanowski - Profesor na Wydziale Samochodów i Maszyn Roboczych Politechniki Warszawskiej.

e-mail:antoni.szumanowski@simr.pw.edu.pl 